\title{
LEAN Management Tools Implementation for the Impact Study in the European Foundation for Quality Management Model Score
}

\author{
Fernando Acabado Romana ${ }^{\circledR}$, Carlos Guillen Gestoso ${ }^{(1)}$ \\ Department of Management Sciences, Atlantica University, Barcarena, Portugal \\ Email: fromana@uatlantica.pt, carlos.guillen@uca.es
}

How to cite this paper: Romana, F. A., \& Gestoso, C. G. (2022). LEAN Management Tools Implementation for the Impact Study in the European Foundation for Quality Management Model Score. Open Journal of Business and Management, 10, 39-56. https://doi.org/10.4236/ojbm.2022.101003

Received: November 4, 2021

Accepted: December 14, 2021

Published: December 17, 2021

Copyright $\odot 2022$ by author(s) and Scientific Research Publishing Inc. This work is licensed under the Creative Commons Attribution International License (CC BY 4.0).

http://creativecommons.org/licenses/by/4.0/

\begin{abstract}
The main objective of this article is the description, analysis and explanation of the development of an integrated management model, supported by the LEAN management tools, for manufacturing companies that worked along the time on a mass production basis. The methodology used was the integration of a model supported by the EFQM-European Foundation for Quality Management system, with the principles, tools and indicators of the LEAN management tools. The fundamental discoveries found in the analysis and application of the case study are located in four fundamental aspects, related to the definition of a purpose for the company, the clear and correct description of the business processes involved, the involvement of people and teams and the application of a thought of continuous and permanent improvement. From the point of view of added value for organizations, we understand that the levels of productivity, competitiveness and value creation for shareholders are the increasingly important elements of action, and the promotion of the implementation of models that promote cost reduction and increased product quality levels are absolutely essential. The recommendations are for the implementation of new management philosophies based on the integrated behavior of continuous improvement, reduction of waste in processes and activities and constant monitoring of results through the correct application of management indicators.
\end{abstract}

\section{Keywords}

LEAN, Management, Model, System, Tools

\section{Introduction}

Companies in general, even those that are mature and implemented in the mar- 
kets, are often faced with new demands and changes in the markets in which they operate, which promote a need for great adaptation and flexibility in their business management processes. The constant changes in processes tend to promote increases in productivity, cost reduction, increase in quality levels and reduction of activities without added value for customers.

One of the solutions understood as possible is the creation, development and implementation of an integrated management model, in which the application of LEAN management principles supported by the EFQM model is presented and proven to be very interesting.

This philosophy is characterized by the constant search for perfection through the reduction of tasks without added value, while optimizing quality levels. Thus, our study studied understanding a case of implementation and improvement of the organization's results.

For this purpose, we developed the practical implementation of a management model supported by the integration of the EFQM models and LEAN management philosophy, and this work aims to understand this reality in an industrial company manufacturing metal parts.

The research structure is based on an initial evaluation of the company model scores and after the research/action process we evaluate the new status of the evolution, always supported by the same score criteria.

\section{Literature Review of EFQM and Lean Management}

The EFQM is the entity responsible for the Excellence Model, which over the past twenty years has been a support structure for European and worldwide organizations to develop a culture of excellence, access good practices, drive innovation and improve their results.

The EFQM Excellence Model consists of three integrated components:

The Core Concepts of Excellence-Define the underlying principles for an organization to achieve sustained excellence;

The EFQM Criteria-Converts Core Concepts into a management tool;

RADAR-Simple but powerful tool to drive systematic improvements in all areas of an organization. The EFQM Excellence Model is used as the basis for the (self) evaluation of an organization, an exercise through which it is evaluated against a set of 9 detailed criteria, which are based on the 8 Fundamental Concepts of Excellence, and scored through of the RADAR. As a management tool, it allows:

Assess the organization's performance and identify strengths and areas for improvement;

Integrate and align existing processes, procedures and tools, eliminating duplication;

Introduce a culture of continuous improvement;

Identify which actions are actually having a positive impact on results, which areas need more attention and which approaches should be made redundant. 
The use of the Excellence Model ensures that all the management practices of an organization form a coherent system, which is continuously improved, and which supports the execution of the organization's intended strategy. APQ, as a partner entity of the EFQM-European Foundation for Quality Management, is responsible in Portugal for the promotion, training and qualification of professionals within the scope of the Excellence Model and associated methodologies, as well as for the translation and marketing of its materials. APQ is also responsible for managing the Levels of Excellence recognition scheme (Aberta University, 2020).

LEAN Indicators for Productive Stability

Productive Stability is the situation in which the production process or flow is kept as planned, under the view of Takt time and the behavior of 4M's. There are many ways to measure whether a process or flow is stable.

This point aims to point out indicators to monitor production instability, ways of measuring, disclosing and intervening to reduce waste and solve problems (Womack \& Jones, 2011).

For each main or base process such as stamping, assembly, fabrication, painting, heat treatment, injection, etc. The supervisor and the direct manager must prepare the "Daily Production Report", which normally contains five sheets, in A4 format, where the following indicators are generally measured:

- Quantity produced (volume produced according to the production plan);

- Calculation of productivity through the number of hours available, depending on the workforce destined for production;

- "Downtime" (hours when production is stopped due to the occurrence of waste or problems);

- Absenteeism and training (multiplicity);

- Quality.

On the first sheet, the base data reported are the quantity produced, with the production monitoring table reproduced at the bottom for the hourly observation of the appearance of possible irregularities. If no waste or problems occur, then the planned production has to be achieved (Monden, 2012).

Factory level indicators

According to the A3 format, the production planning and control department prepares a monthly report, with the following topics:

- General information;

- Production status;

- Indicators;

- Important points; and

- Perspectives.

In the "General Information" field, the planned X actual production, accumulated in the year, adjustments in the production schedule according to changes in sales data and the need to adjust the Takt Time or not are observed (Womack \& Jones, 2011). 
In the field "Production Status", the indicators measured monthly are available, such as:

- Approved production (units/month);

- Production of spare parts and other factories (units/month);

- Partial productivity of each process and the accumulated for the standard or higher volume (Mh/unit);

- Accident levels (frequency), and this data is handled by the safety and production areas-A4 forms;

- Quality Levels (defects/unit averages);

- Realization of planned investments, in which these data are processed by each responsible area, through the A4 forms filled in by the supervision and leadership;

- Cost reduction by processes (Value/Unit), also through A4 forms issued by the responsible areas;

- Number of implemented suggestions (Quantity/Month);

- Planned and performed maintenance costs;

- Monitoring of energy and water consumption (Value/Unit).

All the above indicators have their goals established by the management (Hoshin) and informed in the previous year, so that each area can prepare its planning and present its A3 document, which informs the concrete actions to achieve the objectives.

In the "Important Points" field, each production area reports the main improvement activities carried out or in progress necessary to achieve the outlined goals, and in the "Perspectives" field, the Production Planning and Control places messages in order to comment on the overall performance the factory according to the objectives set (Basu, 2011).

Monitoring of Indicators

At the process level, leaders, supervisors and team leaders follow each of the indicators described through charts updated daily, displayed in illustrative tables of visual management.

Considering the goals established in the A3 monthly report and the daily analysis of indicators at the process level, deviations from what are established trigger the "chain of help", in order to analyze problems or waste and act according to urgency and need.

At the factory level, indicators are monitored in monthly management meetings, and those outside the plans must be analyzed and discussed by all areas represented, so that everyone can interact in the difficulties and share ideas and new actions.

Results/Link to Management Control/Six Sigma

At this point, we will address some issues through the integration of management, with a view to its follow-up, as well as the possibility of integrating the various tools and philosophies.

Indicators (Most frequent results) 
There are standard levels of improvement, analyzed through experience, in the implementation of LEAN projects, such as the following:

- Costs-30\% - $40 \%$

- Lead Time- $70 \%$

- Productivity-30\%

- Quality-+++++++

- Capacity Release

- Greater customer satisfaction

- Greater Responsiveness

- Expansion of sales

- Sustained results

Management support resources Modern Management Methods

Balanced Scorecard

The Balanced Scorecard is a modern management concept that helps managers to monitor the results of their areas at all levels.

There is nothing new regarding the use of key indicators to track the performance of organizations. The novelty of the (Kaplan \& Norton, 2007) method is that they advocate and recommend that analysis and follow-up be carried out in four areas:

- Financial performance;

- Knowledge of customers;

- Internal business processes;

- Learning and growth.

This methodology allows the monitoring of current performance, but also provides information on how the organization can position itself and predict the future.

The authors cite the following advantages for using the balanced scorecard:

- Focus the entire organization around the actions to be taken to create the highest levels of performance;

- Helps integrate the corporation's various programs, quality, reengineering, and customer service initiatives;

- It unfolds the initiatives that influence strategic indicators for all levels of management, operations and all employees know exactly how to work towards excellent global performance.

Similarities to Hoshin Planning

The balanced scorecard bears strong similarities to Hoshin or Hoshin Kanri planning, the strategic planning development system used by Japanese companies. Both are centered on performance analysis, alignment, and goal integration at all levels. The balanced scorecard what specific areas should be followed resulting in a balanced picture, but this is not contradictory to Hoshin planning. One of the aspects that the Japanese emphasize is the fact that the communication process between the various levels helps to define the companies' strategy. The balanced scorecard seems to be more focused in one sense-executives 
create the strategy, and the strategy is rolled out to lower levels (Basu, 2011).

A warning notes

We always try to achieve the results of the data we measure, so people tend to do everything to reach the stipulated goals. Some authors fear this effect, due to the fact that there is inattention in some aspects of the work motivated by the payment of incentives. For example, emphasizing traditional financial management measures tends to encourage short-term thinking-such as ensuring shipments on time to achieve monthly sales levels, or crafting aggressive discounting policies to achieve annual goals. This is recognized by Kaplan and Norton, so a more balanced set of measurements is needed. Even so, people will work to get their goals recorded on the scorecard and may overlook other important things that aren't in the process.

So, if the scorecard is infrequent and sufficiently revised, an important goal in January may not have a big impact in June.

The authors acknowledge these risks, and do not claim to have had the last word in the development of the scorecards.

Process Improvements

All activities of an organization are part of a process. Processes are supposed to create value, for example, achieving something that was not done at the beginning. Most processes are not optimized-there is usually some wasted effort, wasted time, or scraps, poor communication, or repairs.

All of these problems are sources of cost-some small and some of high value.

Fortunately, people have ideas to improve processes in mind. Management practitioners have, over the years, developed tools that can be used to and systematically make these improvements. It is also important to consider that the focus on the processes, rather than on the people involved in them, results in substantial improvements much more and faster.

Process development and improvement is a key concept for modern management. Some of these aspects are systematized as follows:

Dr. Deming and his famous PDCA model are focused on process improvements.

The model is represented by fourteen points, which serve as guidelines for management. These points cultivate an idea of improvement based on more efficient jobs, greater results and high levels of productivity and growing.

- Create and communicate to all employees the status and purpose of the organization;

- Adapting to the new day-to-day philosophy, industry and economy are constantly changing;

- Create product quality through production;

- Ending the practice of obtaining business based solely on price, but rather trying long-term relationships based on the loyalty and trust created;

- Work to constantly improve quality and productivity; 
- Institute on-the-job training;

- Teach and institute leadership to improve all functions;

- Move forward without fear, creating trust;

- Strive to reduce conflicts between departments;

- Eliminating exorcisms to the workforce, instead creating a focus on system and morals;

- 1) eliminating standard production quotas, replacing leadership methods with improvements; 2) eliminating MBO. Avoid numerical goals. Alternatively, learn the capabilities of the processes, and how to improve them;

- Remove barriers that prevent people from taking pride in their work;

- Educate by creating programs to improve their abilities;

- Include everyone in the organization to effect the transformation.

Comments on some of the points:

The first of the fourteen points encourages managers to the idea of establishing continuous improvement, by redefining the company's purposes. Simply put, the company has to survive, compete and constantly renew its resources for growth and improvement through research and development.

In the fifth point, it is established that only the commitment to an improvement process continues to earn recognition. The company cannot think that creating a good quality situation, at any given time, will prosper forever. Instead, it must adopt a philosophy of evolution, which avoids stagnation and prepares the organization for the uncertainty of the future. Part of this evolutionary mindset is to abandon practices that value short-term benefits that will later undermine the organization's effectiveness (Womack \& Jones, 2011).

Point number four, alerts to the following scenario: the purchasing department of a company consistently values the suppliers that perform the lowest prices. As a result, the company often buys poor quality equipment. What is suggested is that loyalty relationships be established with suppliers of high-quality equipment.

Point three condemns massive inspection and its procedures as inefficient, the product must be monitored by production operators throughout the manufacturing process in order to meet quality requirements. In the long run, the use of better equipment combined with work oriented towards this inspection method will significantly improve productivity and reduce costs. To achieve these goals, the company must consistently develop an active plan that involves its entire workforce in support of a policy of total quality.

Cooperation

This management philosophy is based on an ideal of cooperation. To achieve their full potential, companies have to raise and develop the knowledge and effort of all their employees. For this reason, aspects related to poor service quality and negative attitudes on the part of the organization are refuted.

Deep Knowledge Theory

To promote cooperation, the model exposes the theory of deep knowledge, 
which involves far-reaching views and a strong understanding of all the individual elements that make up the breadth of the company's entire management system. It is believed that all employees have unlimited potential, whenever placed in an environment that favors and supports, educates and nurtures a strong sense of responsibility. The majority of employees' effectiveness (85\%) is determined by their environment and only a minority by their skills.

Managers who intend to establish this type of environment must:

Use a psychological understanding-of the groups and of each individual. Eliminate tools related to production quotas and internal competitive slogans, which will only alienate operators from their supervisors and create divisions between them.

Organizing the company by teams and sub-teams so that they work on different aspects, but with the same goals, in addition, should eliminate barriers between departments that only create unnecessary conflicts.

Share the results among employees as a group and not individually.

Eliminate fears, envy, anger and revenge from the workplace.

Use sensitive methods such as strict workplace training plans.

As a result, employees will gain a better understanding of their functions, specific and technical tasks, as well as their contribution to value creation. The more people stimulated and motivated, the better they perform. The cost of these actions pays itself.

These ideas seem obvious, but they must be included in a work culture, which should lead to a change of mindset. They are based on concepts of sincerity, decency and personal responsibility, forever changing the world of management (Basu, 2011).

"It's not enough to give your best or work hard, you have to know what you're contributing to"-W. Edwards Deming.

Systemic thinking

Whenever you are trying to understand the world, or an organization, or even a small group of people, it helps a lot to think in terms of systems.

Various types of systems:

- Vicious cycle-Deficient education and training causes greater difficulties for the following generations;

- Progressive-Negative attitudes and defense actions are understood as threats by other areas or people, who in turn take the same attitudes, making the effect unavoidable and growing;

- Tragedy of the commons-Lack of understanding between teams and individuals, no one wins and everyone in the organization suffers, usually associated with poor leadership.

Taguchi Methods-Practical and Fast Quality

After World War II, Japanese industries struggled for survival with very limited resources, and if the Taguchi advance hadn't come, perhaps today they wouldn't be the country they are. Taguchi revolutionized the production process 
in Japanese industries, through the logic of cost reduction. The initial understanding, like many others, is that production processes are affected by numerous external factors, noise. Therefore, Taguchi developed methods to identify the sources of these noises that had a huge effect on the variability of the products produced. His ideas have been adopted by successful manufacturers around the world, as they achieve high levels of production at lower costs.

Here are some of Taguchi's main contributions that have improved quality levels around the world:

- The loss function-Creates a quantified relationship between the customer's understanding of the decline in value of a product when its quality level drops. It tells managers what their loss in sales is due to the variability of their production process. It is a powerful tool for projecting the benefits of a quality improvement program. It was the first approach to link quality with cost.

- Orthogonal analysis and linear graph-When evaluating a production process, external factors that cause deviations in results and means will be identified. Isolating these problems can place a high level of work and cost on the process. For this, Taguchi developed the use of orthogonal analysis in a more efficient way in terms of time and cost.

- Robustness-Some negative effects on processes can be identified, isolated and even eliminated, but others cannot. For example, it is very difficult to predict and prepare for possible climate change. Even so, Taguchi developed a technique based on the robustness of the processes to be cautious and able to operate, even in adverse conditions. In a way, it allows some companies to develop products and processes that work evenly, even under uncomfortable conditions and forces, which is an obvious benefit for the service provided.

Productivity - How can it be improved?

We can always improve and develop natural resources, equipment, animals and even ourselves for the production of goods and services. If we are talking about the productivity of a natural resource, we are managing it in terms of the production rate per hectare, or cubic meters of gas. Equipment productivity is usually expressed as production per hours. People's productivity varies between pure quantitative work, that is, the number of pieces per hour, or something subtler-like the number of ideas in a given period or cycle.

Over time, people have become more and more productive, in a place where 16 tons were produced 100 years ago, 1000 tons can now be produced.

More productive companies tend to earn more than less productive competitors, as their costs are lower for the same level of production. So how can management act to increase productivity?

1) Make sure the entire organization is acting in the same direction and this is correct and clear. If they circulate in different logics towards the common goal, they are wasting time and energy;

2) Make sure communication is clear, fluent and clear. If everyone is aligned, less time and energy is wasted; 
3) Make sure you detect problems as early as possible, and quickly isolate them;

4) Make sure that people's efforts and time are not wasted on solving imaginary problems. If methods or control frameworks of key processes are used, we will always be able to distinguish differences and changes in the environment and processes;

5) Develop people's minds. You usually feel that you are being constrained to do your job. They must be questioned, listened to and involved in solutions;

6) Remove barriers to progress systematically. Avoid waste. Avoid repairs. Reduce inspection to a minimum;

7) Understand the real costs. How much does a person actually cost? How much does a device actually cost? Can a process be better conducted outside the organization?

Almost all of these aspects are mentioned here because they contribute to improved productivity. They are not exclusive. All these aspects can be combined into a cohesion program, which in the end translates into good management.

Applying these tools helps lead the organization and can lead to higher levels of productivity.

Six Sigma in Quality

What is Six Sigma in Quality, and why is it a management topic?

Six Sigma in Quality is a movement that derives directly from TQM "Total Quality Management”.

It uses practically the same tools and the same concepts, but Six Sigma has two new emphases, which are distinctive features:

1) Six Sigma "Black Belts"-experts heavily trained in quality, process improvement and statistical control-who work in organizations to solve problems. They lead process improvement projects and focus on areas that have a strong impact on results.

2) Focus on reducing variations to very low levels.

As a strategy to improve results, it harmonizes quality programs and can be applied to companies of all sizes in any field of activity (Basu, 2011).

\section{Case Study in Practice}

After analyzing the literature, it is clear that the combination and integration of the EFQM management model, with the LEAN management philosophy, must be addressed and confirmed with a case study, to assess the practical component of its application (Kamal, 2009). Thus, we will understand the description of the analyzes carried out and the evolution of various LEAN management indicators, combined with the various factors involved in the EFQM model, for which we have developed its application in an industrial unit for the manufacture of metal parts, in a forging process and presses, developing the explanation of the practical case according to its various stages of creation and objectives, development 
and implementation and monitoring of results through indicators.

The global management model will be the guide and fundamental objective of action, which will be characterized by the pillars of the model itself, consolidated and sustained, by the context of action, the involvement of stakeholders, the leadership style and the strategies developed to achieve its real-time application, thus reaching a global management model (Kokubu \& Tachikawa, 2013).

The philosophy and principles of strategic action for the creation of the general model, in this case study, is clearly, as defined in the literature, the definition of values and pillars, leading to the path to excellence, which in this case are development of high levels of communication, fostering teamwork, participation, involvement and commitment of people, listening to and visiting customers, working with quality and safety and being resilient (Sygulla, Bierer, \& Götze, 2011).

The characterization of the EFQM model will be represented in Figure 1, through the modular scheme and developed by the organization itself, which allows us to also understand its application to the case study, combining its components and elements, with the strategic plan, with the model of follow-up, perception of customers and employees, management of sustainability processes and procedures.

In defining each phase of the application of the analysis model to the case study, the LEAN-DMAIC-Define tool was used; Measure; Analyze; Improve and Control, as the guiding guide for the implementation and management sequence of the global model, referring to the company represented in the case study (Basu, 2011).

In the define phase, we explain the reason and explanation of the purpose of carrying out the project, in the measure phase, we identify and measure the current situation of the organization against the elements of the model and the respective indicators, in the Analyze phase, we understand the deviations, gaps, obstacles and causes of problems, in the improve phase, we develop and apply action plans to improve the situations found in the previous phase and in the control phase, we prepare reports, identify risks and the evolution of results (Basu, 2011).

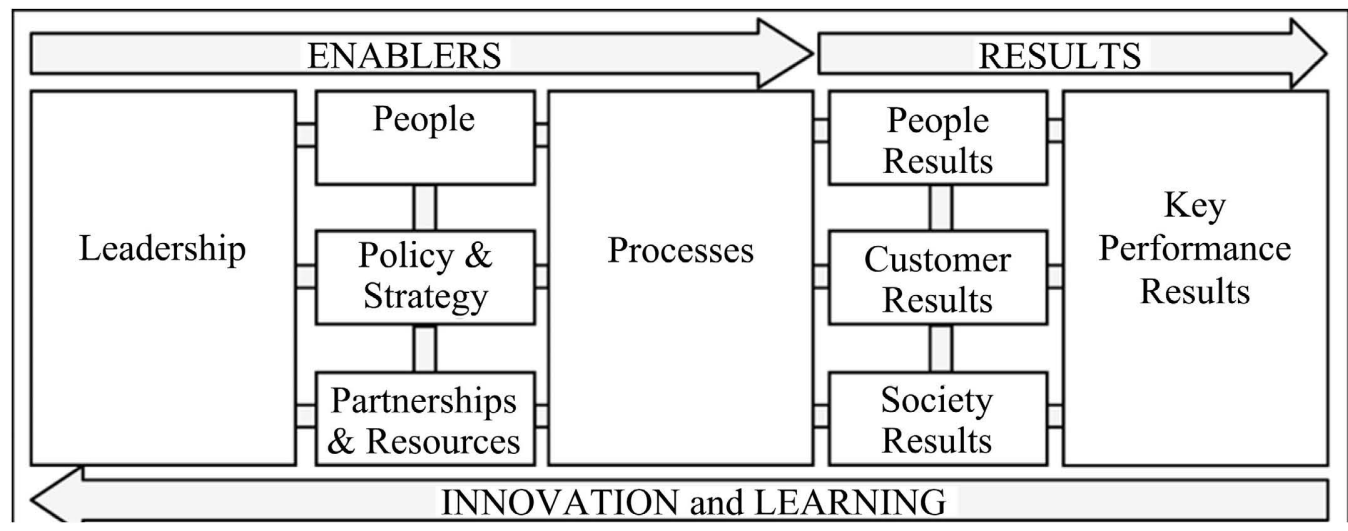

Figure 1. European foundation model for quality management. Source: EFQM, 2020. 
From the point of view of the presentation of reports and results and in methodological terms, we use the Balanced Scorecard management tool, which allows us to organize the monitoring indicators by categories.

The ScoreCard is divided into four fundamental areas, which include indicators by different categories, such as the financial quadrant, the customers quadrant, the quadrant related to internal processes or operations, and the learning and growth quadrant (Kaplan \& Norton, 2007).

In the financial quadrant, we will have as fundamental indicators Cash Flow and EBITDA; In the customers quadrant, sales are growth and competition; In the internal processes and operations quadrant, the capacity, efficiency and quality indicators; and in the learning and growth quadrant, we will have indicators of innovation in new products and behavior related to people management, with particular emphasis on training (Kaplan \& Norton, 2007).

The EFQM model is characterized by two fundamental areas (Figure 1), the first related to the means or elements of action and the second related to the results. The first area comprises elements related to leadership, people, policy \& strategy, partnerships \& resources and processes. The second area is made up of elements relating to people, customers and social results, culminating in performance indicators.

The model's global score is 1000 points, with the respective weights being different between the various elements and represented in Graph 1.

The graph represents the global distribution of the importance of the score by elements, after which we must evaluate each organization according to each aspect in real terms.

In our case study and after the initial evaluation of the model elements, applied to the real themes of the company under analysis, we were able to obtain an overall score of 540 points $(1000 \times 54 \%)$, distributed according to Graph 2 .

\section{EFQM weights per element}

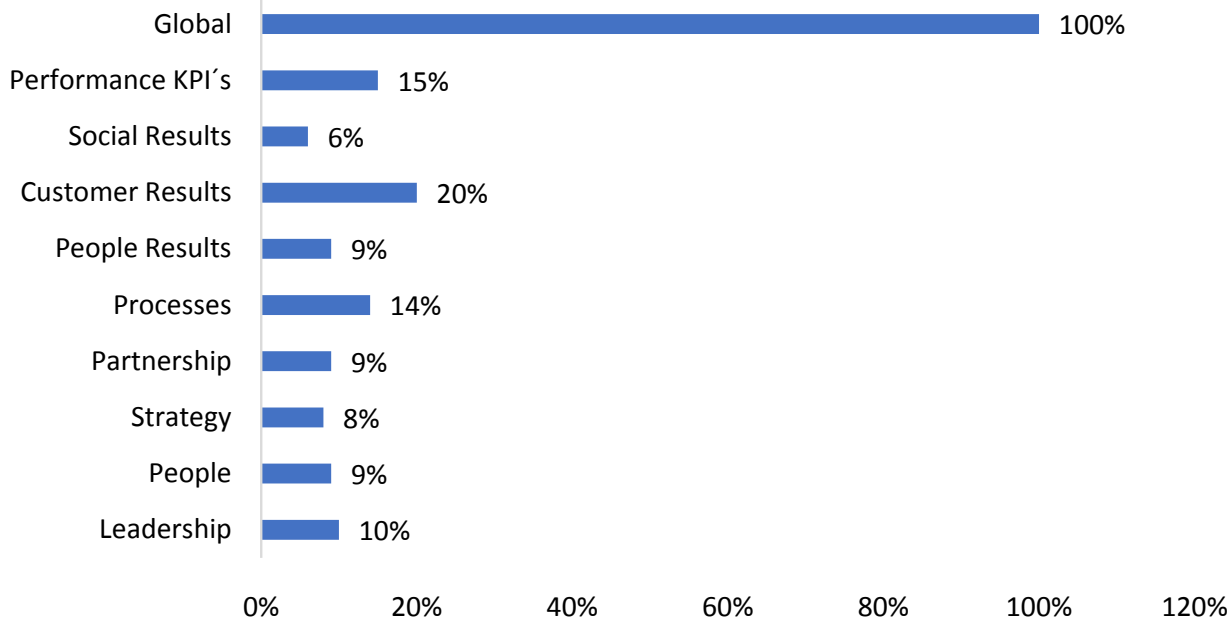

Graph 1. EFQM weights per element. Source: EFQM 2016. 


\section{Inicial Evaluation Model}

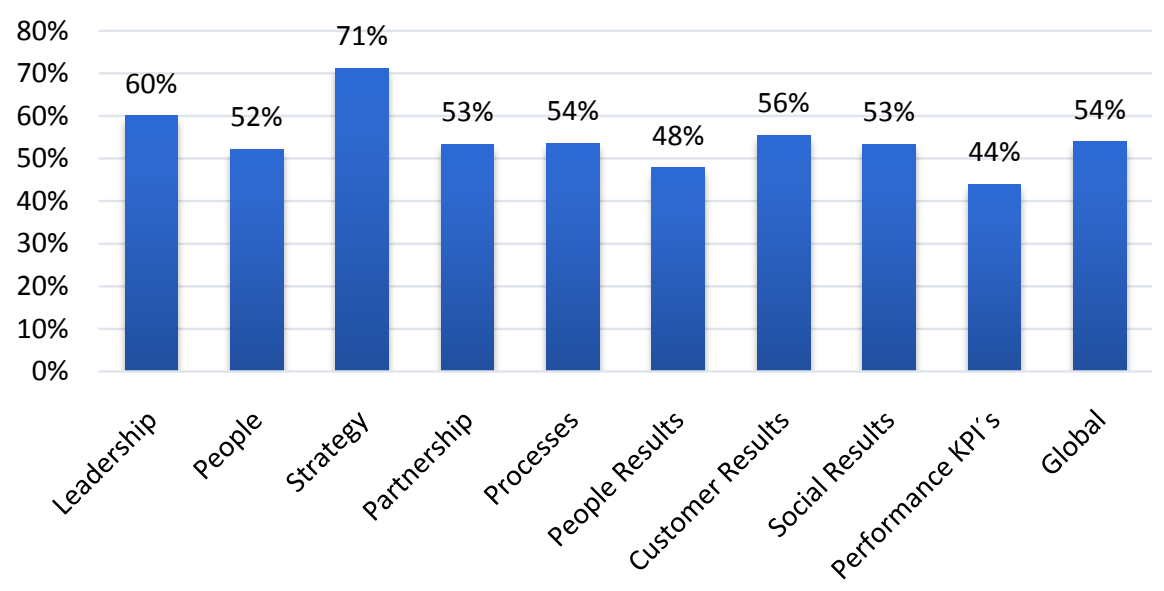

Graph 2. EFQM weights per element applied on the case study company. Source: company data.

The distribution by areas and by elements is represented in \%, which in turn represents the part of the 540 points that will be assigned to each factor, as all \% are based on the total 1.000 points.

The new Operational Management Model

To start the development and implementation of the new management model, the basic principles of action were developed, considering Drucker's path to excellence, studied in Romana (2016b), which should be understood as follows:

- Customer Enthusiasm-our Customers' interests always come first. We are committed to products, services and solutions, supported by attitudes that create enthusiasm in our customers.

- Trusted Relationships-we expect our people to put trust and respect in everything we do.

- Integrity-we are committed to complying with all laws, regulations and ethical principles that apply to us. We will protect and keep confidential all information we receive from customers and other business partners.

- Social Responsibility-we maintain cordial relationships with the community and with all official entities with which we interact.

- Dedication to Excellence-we are determined to achieve the highest levels of Excellence in everything we do. Our future success depends crucially on adopting the absolutes of Excellence.

As part of the creation of a common behavior model, the absolutes of excellence were also developed, which are guided by various attitudes, both internal and external (Sygulla, Götze, \& Bierer, 2014):

- Caring for Customers;

- Respect for People;

- Ethics and Social Responsibility;

- Health, Safety and Environment; 
- Recognition of Workers and Partners.

These aspects allow, on the one hand, the common action of the entire organization, as well as a more careful and professional approach to stakeholders and the environment (Romana, 2016a).

To make the company's management methodology more effective, a risk-based management spirit was also instilled, whereby the integrated operating model is developed in accordance with the principles appropriate for the organization.

In the current context in which change is a constant, shareholders have been demanding greater transparency about the risks faced by organizations. There is a growing recognition that proactively and integratedly coordinating all risks is critical to success, so traditional Risk Management approaches are no longer sufficient (Guenther, Jasch, Schmidt, Wagner, \& Ilg, 2015).

Therefore, the company will choose to implement a business risk management model, considering the integration of all its areas, processes and activities, highlighting the definition of priorities according to the highest risk levels (Romana, 2016b).

We develop our model in the following five areas:

\section{- Market risk}

Measured by sales results and margins against budget, BCG matrix and five forces diagram.

- Credit Risk

Considering the approval and credit policy to be granted, insurance and obtaining credit from third parties and banking.

- Operational Risk

Company brand image and reputation (NPS), product quality, project development, contingency and incident recovery plans (DRP).

- Legal Risk

Contract management, present and future litigation, compliance with commercial, labor and tax legislation.

- Information and Communication Systems Risk

Classification of necessary information as "Confidential" and security of information and management systems.

Which allow the consolidation of the integrated risk management model, in accordance with the correct identification and analysis of the environment and organizational strategy.

Stakeholders, value creation and the operational management model

The generic management model is characterized by the integrated and sequential action of the four fundamental areas of its composition, based on the LEAN management philosophy (Spear, 2004). The conceptual scheme of the model is reflected in Figure 2.

The fundamental areas of action are related to the clear definition of the purpose of carrying out the management actions, the involvement of people at all levels, description and management by the organization's processes and implementing 


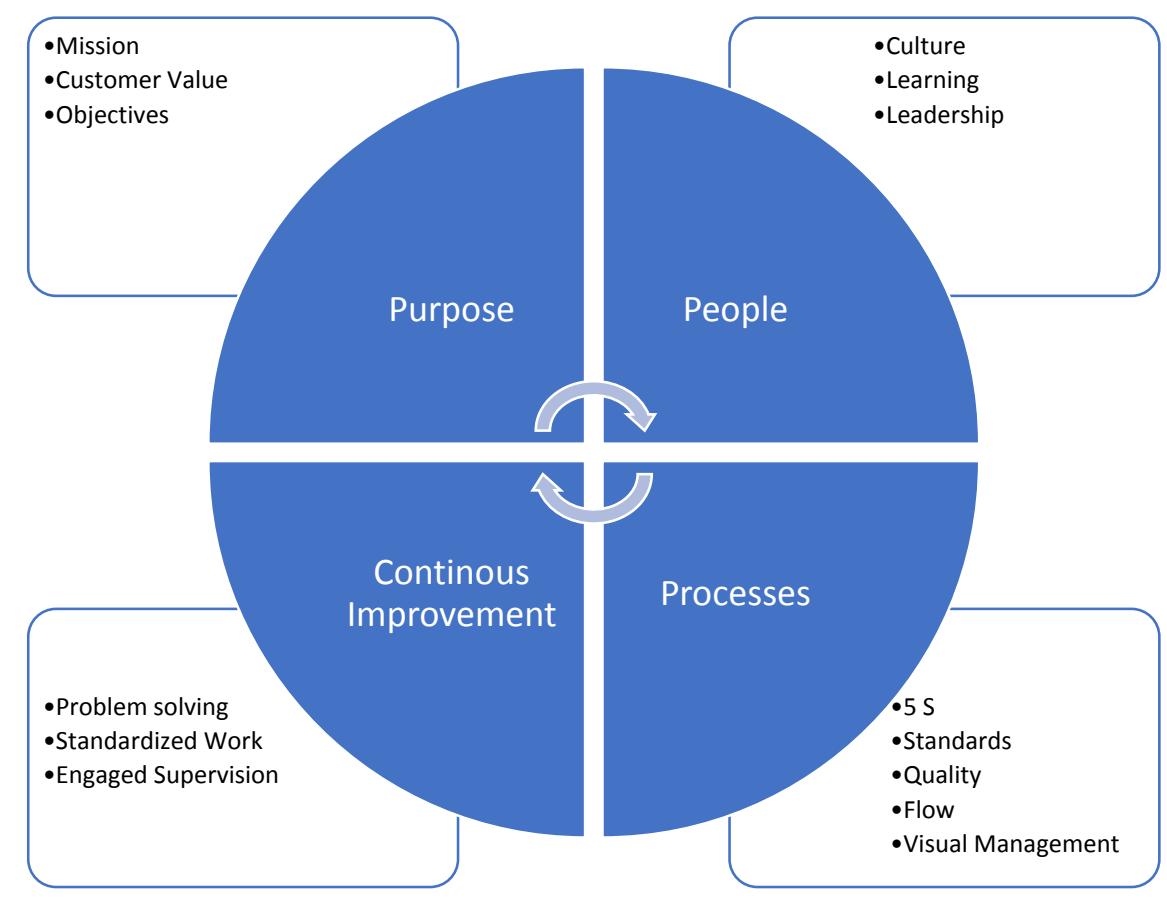

Figure 2. Conceptual scheme of the general model. Source: performed by the author.

a spirit of action of continuous improvement based on the constant application of the PDCA cycle-Plan; Of; Check; and Act (Womack \& Jones, 2011).

The results obtained with the application of the new operational management operational model, Sobek \& Jimmerson (2004), reflected in Graph 3, which represents the element of the Balanced Scorecard system related to operational processes and composed of indicators related to the performance of the aforementioned processes, which are Christ \& Burritt (2016).

- Better internal instructions between areas (1);

- Improve reaction to error correction (2);

- Get it right the first time by reducing unforeseen operations (3);

- Improve supplier selection (4);

- Greater attention to customers to avoid problems and unnecessary rework (5).

The results are shown in Graph 3, in percentage values, which show the evolution of improvements in each of the processes (Schmidt, Götze, \& Sygulla, 2015).

We should now understand the impact on new actions to improve operational indicators and implement new management philosophies, in the EFQM model, related to the following year of application, starting in March 2019 and the second assessment in December 2020.

The new values are reflected in Graph 4, which represents the elements of the EFQM model, with the calculation and identification of new values, after the implementation of improvements and the impact of operational indicators.

As we can see in the graph, there is a clear overall improvement in the organization, increasing the global score from 540 (54\% of 1.000$)$ points to $660(66 \%$ 
(1) Internal Intructions

(2) Error Correction

(3) First Time Quality

(4) Supplier Selection

(5) Rework

Graph 3. Key performance indicators for operational processes. Source: company data in internal reports.

\section{Model Evaluation after new system}

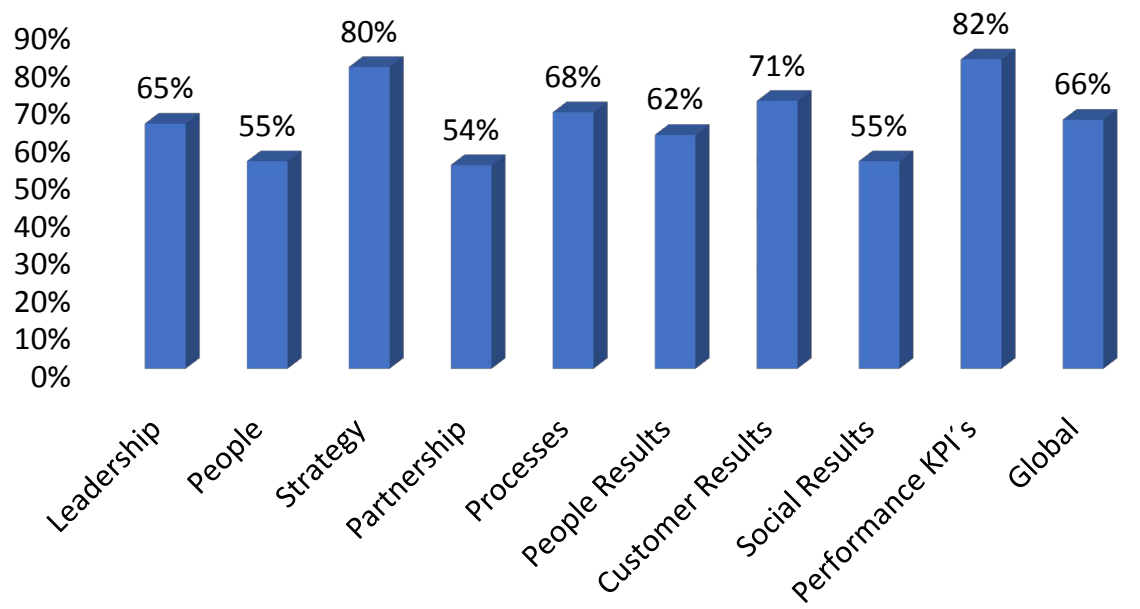

Graph 4. New EFQM values. Source: Performed by the author using company data.

of 1.000) points, with the main contributions to the improvements occurring in the elements related to leadership, definition of strategy, customer results and implementation of new management indicators.

We also consider an important improvement at a general level, and it is naturally visible that the organization should continue the improvement procedures, and it continues aiming at more ambitious values for the years 2021 and beyond.

\section{Conclusion}

The work reported in this article aims to analyze the impact of implementing a management model, supported by the LEAN management tools, on the quality of global management of organizations, assessed by the EFQM-European 
Foundation for Quality Management Model.

According to the existing literature, relationships between the EFQM assessment elements and the operational indicators were developed, related to the measurement of process performance, supported by the performance of lean methods and tools and associated management indicators.

The method used to evaluate the aspects mentioned in the literature, with the practice of organizations, was the application of the models in a concrete case study, in an industrial company dedicated to the manufacture of metal parts.

In terms of results, we were able to understand two complementary situations, the first being related to improvements in the company's operational indicators, through the application of the new management model supported by the lean philosophy, and the second, related to the overall improvement in the quality of management, referenced in the values obtained by applying the analysis supported by the EFQM model through the impact of improving the performance of operational processes.

In terms of recommendations for the future, we find it interesting to disclose the implementation of the model in several organizations, which after being tested becomes relatively easy to apply, also understanding that there may be some limitations, due to the diversity of processes existing in the different sectors of activity, since the case study contained in this work is focused on a manufacturing activity, as we already did it on a global philosophy supported approach.

\section{Conflicts of Interest}

The authors declare no conflicts of interest regarding the publication of this paper.

\section{References}

Aberta University (2020). Site Statement on Total Quality Management Integrated Models. Aberta University Web Library.

Basu, R. (2011). Implementing Six Sigma and Lean: A Practical Guide to Tools and Techniques. Butterworth-Heinemann.

Christ, K., \& Burritt, R. (2016). ISO 14051: A New Era for MFCA Implementation and Research. Revista de Contabilidad, 19, 1-9. https://doi.org/10.1016/j.rcsar.2015.01.006

Guenther, E., Jasch, C., Schmidt, M., Wagner, B., \& Ilg, P. (2015). Material Flow Cost Accounting-Looking Back and Ahead. Journal of Cleaner Production, 108, 1249-1254. https://doi.org/10.1016/j.jclepro.2015.10.018

Kamal, M. (2009). Injection Molding: Introduction and General Background. Carl Hanser Verlag GmbH \& Co. KG. https://doi.org/10.3139/9783446433731.001

Kaplan, R., \& Norton, S. (2007). Time Driven Activity Based Costing: A Simpler and More Powerful Path to Higher Profits. Harvard Business School Press.

Kokubu, K., \& Tachikawa, H. (2013). Material Flow Cost Accounting: Significance and Practical Approach? In J. Kauffman, \& K. M. Lee (Eds.), Handbook of Sustainable Engineering (pp. 351-369). Springer. https://doi.org/10.1007/978-1-4020-8939-8 96 
Monden, R. (2012). TQM Integrated Models. Harvard Business School Press.

Romana, F. (2016a). Lean Management and Organizational Behavior. Bubok Publications.

Romana, F. (2016b). Lean Marketing and Consumption. Bubok Publications.

Schmidt, A., Götze, U., \& Sygulla, R. (2015). Extending the Scope of Material Flow Cost Accounting-Methodical Refinements and Use Case. Journal of Cleaner Production, 108, 1320-1332. https://doi.org/10.1016/j.jclepro.2014.10.039

Sobek, D., \& Jimmerson, C. (2004). A3 Reports: Tool for Process Improvement. In IIE Annual Conference Proceedings (pp. 1-6).

Spear, S. (2004). Learning to Lead at Toyota. Harvard Business Review, 82, 78-86, 151.

Sygulla, R., Bierer, A., \& Götze, U. (2011). Material Flow Cost Accounting-Proposals for Improving the Evaluation of Monetary Effects of Resource Saving Process Designs. In Proceedings of 44th CIRP Conference on Manufacturing Systems Program (pp. 1-3).

Sygulla, R., Götze, U., \& Bierer, A. (2014). Material Flow Cost Accounting: A Tool for Designing Economically and Ecologically Sustainable Production Processes. In E. Henriques, P. Pecas, \& A. Silva (Eds.), Technology and Manufacturing Process Selection (pp. 105-130). Springer. https://doi.org/10.1007/978-1-4471-5544-7 6

Womack, J., \& Jones, T. (2011). Lean Thinking. Harvard Business School Press. 